\title{
VARIATIONS WITH DISTENSION IN THE WALL AND EPITHELIUM OF THE BLADDER AND URETER.
}

\author{
$\mathbf{B Y}$ \\ RICHARD W. HARVEY. \\ From the Anatomical Laboratory of the University of California.
}

With 5 figures and 1 Table.

For some years during the usual class work in histology in this laboratory, comparisons of the distended bladder epithelium with that in the contracted state have given rise to the impression that in the thinning consequent to distension, the cells of the epithelium were not only flattened, but also were to some extent actually displaced from their relative positions. This impression has suggested this paper, the purpose of which is to describe some variations in the wall, and in the epithelium alone, of the bladder and ureter occurring with their distension.

Material and Methods.-The bladder and the attached ends of the ureters were removed from a freshly killed dog. A portion of the bladder was tied off so that the fluid used in distending the remainder could not enter it, and ligatures were applied to the ureters close to the bladder. Then, by means of a large syringe, Zenker's fluid was forced into the bladder, by way of the urethra, until it attained about the condition of maximum normal distension with urine and a ligature was applied to retain the fluid. The distended bladder, together with the contracted portion which had been tied off, were then immersed in Zenker's fluid, and, of course, became fixed in the condition in which they were when immersed. A piece of one of the ureters about four inches long was removed, and a ligature was applied about its middle. Into one end, the syringe, filled with Zenker's fluid, was inserted, a ligature loosely applied and then a pressure of the syringe was applied until no further extension was possible. The syringe was then removed at the same time that the ligature was tightened. The thus distended portion 
of the ureter, together with the contracted portion, was then immersed with the bladder in Zenker's fluid for complete fixation.

Pieces for study were cut from the contracted and distended bladder and ureter, washed, dehydrated carefully and embedded in paraffine. In cutting the sections, care was taken to cut perpendicular to the surface of the epithelium. The sections were stained in haemotoxylin and congo red, the latter being chosen as the counterstain because of its efficiency in bringing out cell boundaries.

Variations in the Wall of the Bladder.-Measurements were taken of the entire wall of the bladder in the contracted and distended conditions, the averages in micra being recorded in Table 1. A comparison of these results shows that the thickness of the entire wall in a distension about equal to the condition of maximum normal distension with urine, is about one-tenth that in contraction, -or decreases 90.7 per cent. with distension.

The thickness of the muscularis in distension is about onetwelfth that in contraction, or it decreases 92 .per cent. with distension. The muscle fibres of the bladder are very much extended during distension. In extreme distension the amount of thinning is aided by the power of distension of the connective tissue to which the muscle fibres are attached. The bladder wall, therefore, with regard to its connective tissue component, at least, is in part like a true elastic membrane in extreme distension, in that, to a certain extent, it relaxes of its own elasticity.

Distension of the tunica propria of the bladder, under the same pressure, of course, as the muscularis, reduces its thickness to onefourth that in contraction, or it decreases 74 per cent. with distension. The difference between the variation of the tunica propria and that of the muscularis is probably accounted for by the fact that during the later stages of contraction of the bladder, tunica propria is thrown into folds along with the epithelium.

Variations in the Wall of the Ureter.-In one respect is the distension of the wall of the ureter quite different from the distension of the bladder wall. The distensibility of the bladder has no definite limit. Pressure exerted will gradually and continuously distend 
the bladder until its walls become so thin as to burst, so great is the elasticity of the connective tissue. The distensibility of the ureter is more limited. In distending this, a point is reached at which considerably greater pressure than that used with the bladder fails to further distend it, a definitely fixed limit of distension becoming very apparent. This is indicated in Fig 1 . A, of this figure, shows the relaxed ureter with the characteristic folds in its epithelium and tunica propria; B, shows the ureter fixed under extreme distension from the application of pressure probably suf-

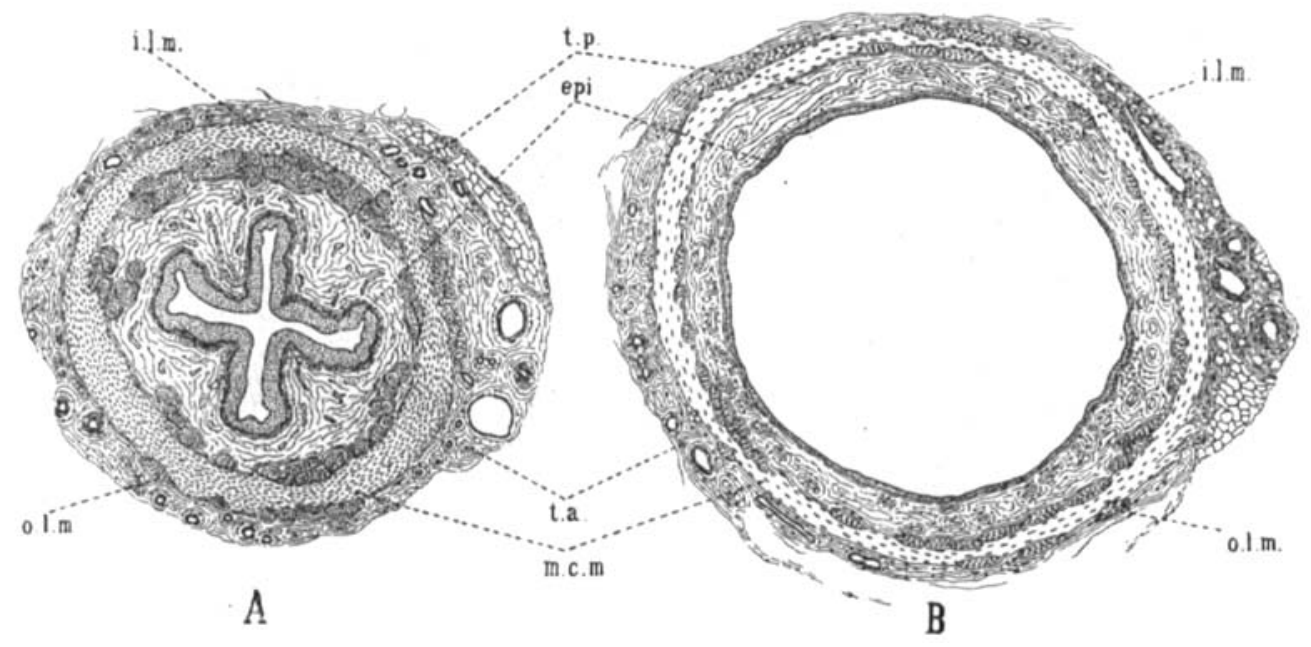

Fra. 1.--Drawings of A, contracted and B, distended ureter showing limits of distensibility. The two are drawn to scale; epl., epithelium; t.p., tunica propria ; 1.l.m., inner longitudinal muscle layer; m.c.m., middle circular muscle layer; o.l.m., outer longitudinal muscle layer; t.a., tunica adventitia.

ficient to burst the bladder wall. The arrangement and abundance of the supporting tissue, and the more organized arrangement of the muscular investment of the ureter, undoubtedly account for the difference between it and the bladder.

Measurements were taken of the entire wall of the ureter, as in the case of the bladder, in the contracted and distended conditions, the average in micra being recorded in Table 1 . Comparing these results it is shown that the thickness of the entire wall of the 
ureter in contraction is two and three-quarter times that in distension, or the thickness of the wall is reduced 63.7 per cent. by distension, instead of the corresponding decrease of 90.7 per cent. in the case of the bladder wall.

The distended muscularis of the ureter is about one-half as thick as in contraction, or the muscularis is reduced 56 per cent. in thickness by distension, instead of 92 per cent., as was that of the bladder. The distended tunica propria is likewise about one-half

TABLE 1.

\begin{tabular}{|c|c|c|c|c|c|c|c|c|c|c|c|}
\hline & & \multicolumn{2}{|c|}{$\begin{array}{l}\text { Thickness of } \\
\text { Entire Wall }\end{array}$} & \multicolumn{2}{|c|}{$\begin{array}{l}\text { Thickness of } \\
\text { Muscularis }\end{array}$} & \multicolumn{2}{|c|}{$\begin{array}{l}\text { Thickness of } \\
\text { Tunjca Propria }\end{array}$} & \multicolumn{2}{|c|}{$\begin{array}{l}\text { Thickness of } \\
\text { Epithelium }\end{array}$} & \multicolumn{2}{|c|}{$\begin{array}{l}\text { Layers of } \\
\text { Nuclei }\end{array}$} \\
\hline & & Micra & $\begin{array}{c}\text { Per } \\
\text { Cent. } \\
\text { Decr. }\end{array}$ & Micra & $\begin{array}{c}\text { Per } \\
\text { Cent. } \\
\text { Decr. }\end{array}$ & Micra & $\begin{array}{c}\text { Per } \\
\text { Cent. } \\
\text { Decr. }\end{array}$ & Micra & $\begin{array}{l}\text { Per } \\
\text { Cent. } \\
\text { Decr. }\end{array}$ & Number & $\begin{array}{l}\text { Per } \\
\text { Cent. } \\
\text { Decr. }\end{array}$ \\
\hline \multirow{2}{*}{$\frac{\frac{5}{\frac{5}{2}}}{\frac{\pi}{x}}$} & Contr. & 5236.1 & & 4762.8 & & 301.2 & & 172.0 & & 4.37 & \\
\hline & Dist. & 486.4 & 90.7 & 382.8 & 92.0 & 76.0 & 74.7 & 27.6 & 84.0 & 2.25 & 48.5 \\
\hline \multirow{2}{*}{ 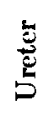 } & Contr. & 751.3 & & 243.4 & & 239.4 & & 268.5 & & 7.67 & \\
\hline & Dist. & 272.6 & 63.7 & 108,0 & 55.6 & 116.8 & 51.2 & 47.8 & 82.2 & 4.00 & 47.8 \\
\hline
\end{tabular}

TABLE 1.-Recording, in micra and percentages of decrease, variations in thickness of the wall, and variations in number and percentages of decrease of the layers in the epithelium of the dog's bladder and ureter in the contracted and distended conditions.

as thick as in contraction, undergoing a reduction of 51.2 per cent. in distension. The close approximation of these variations in the muscularis and tunica propria of the ureter is probably accounted for by the fact that contraction of the ureter does not result in such extensive folds in its tunica propria and epithelium as occur in the contracted bladder, where the difference in the variation of muscularis and tunica propria is about four times as great as that of the ureter. The average thicknesses in micra of the muscularis and tunica propria are recorded in Table 1. 
Variations in the Epithelium of the Bladder and Ureter.The contracted bladder epithelium has the appearance illustrated in Fig. 2. The arrangement consists of a basal layer (a) of cubical cells resting on the tunica propria; a middle layer (b) composed of approximately three layers of irregular, polygonal, or elongated cells; a superficial layer (c) of large ovoid cells from whose under surfaces processes fit into the interstices between the cells of layer (b). The nuclei are full and spherical and the cell boundaries fairly distinct.

Variations in Thickness.-Measurements taken of the epithelium of the bladder in the contracted and distended conditions show that

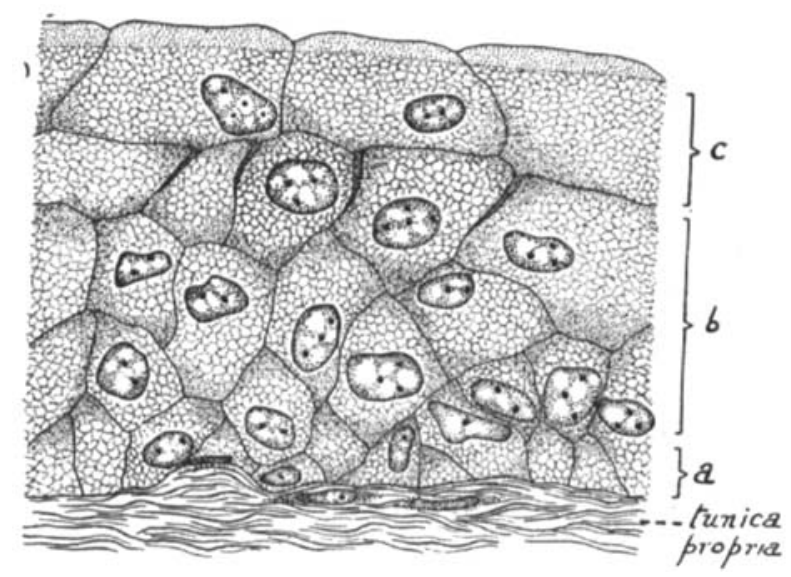

FIG. 2.-Contracted bladder epithelium, drawn with camera lucida. $\times \mathbf{7 5 0}$.

the thickness in distension is about one-sixth that in contraction, or that it decreases 84.0 per cent. with distension. Measurements of the ureter show that the thickness of the epithelium in distension is between one-fifth and one-sixth that in contraction, or that it decreases 82.2 per cent. with distension (see Table 1). Comparing these measurements, there is a difference between the two in percentage decrease with distension of only 1.8 per cent. Thus while the distension results in approximately the same degree of distension in the epithelium of the two organs, the effects are noticeably greater on the muscularis and tunica propria of the bladder than on the correspond- 
ing parts of the ureter. This difference between the two is explained as due to the fact that the bladder is capable of, and customarily undergoes, greater extension than the ureter and, when fully contracted, its epithelium is thrown into larger and more extensive folds than that of the ureter. The similar effect upon the epithelium of the two is of interest as indicating a probable proportional arrange-

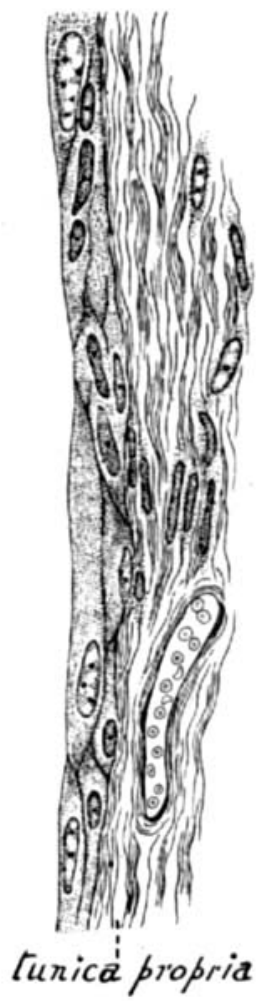

FIG. 3.-Distended bladder epithelium, drawn with camera lucida. $\times \mathbf{7 5 0}$.

ment of the different coats protective against stretching the epithelium to an injurious extent.

In the distended condition, the bladder epithelium appears as in Fig. 3. The basal layer is so flattened that it is somewhat confused with the connective tissue cells of the tunica propria. The middle layer is represented by a few straggling nuclei; and the saperficial 
layer is greatly elongated and flattened, the interstitial processes being nowhere in evidence. The nuclei are greatly elongated and flattened, and the cell boundaries of only the superficial cells are found distinctly evident throughout. Elsewhere the boundaries appear discontinuous and in fragments, as though the cytoplasm of adjacent cells has fused in places, or distension has rendered the membranes so thin as to be invisible.

An ubservation of the arrangement of the nuclei was found useful

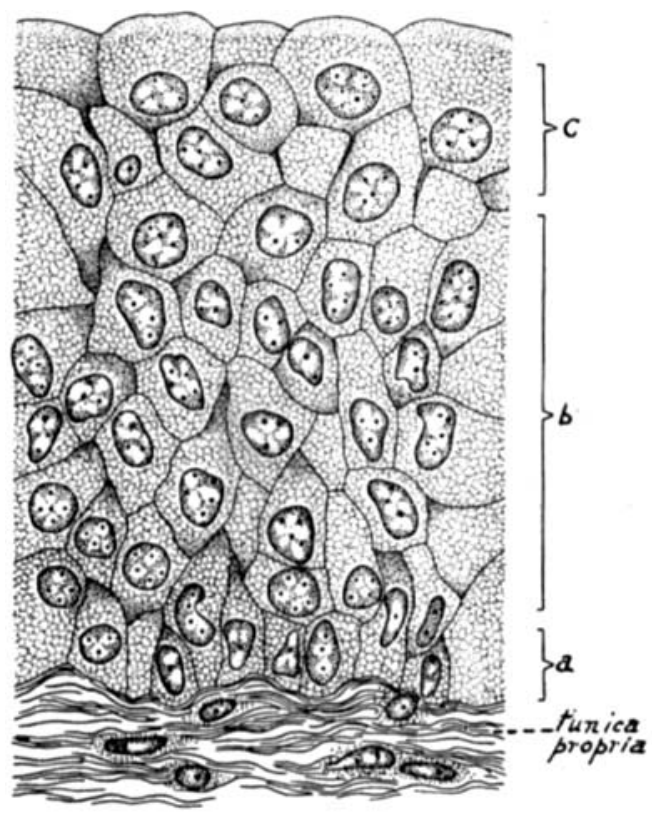

Fig. 4.-Contracted ureter epithelfum, drawn with camera lucida. $\times 750$.

in the study of the structure of the epithelium. This observation was made by counting the nuclei lying in the same focal plane from the basal to the superficial layer. The results of counts taken in different regions of the bladder under the same conditions of contraction and distension are recorded in Table 1 . It will be seen that distension reduces the number of rows of nuclei 48.5 per cent, or approximately one-half.

The epithelium of the ureter is of the transitional type, but 
relatively thicker in the contracted state than that of the bladder, and disposed in more constant folds, Fig. 1, A. In the contracted state, three lavers, comparable with those of the contracted bladder epithelium, are defined, Fig. 4. However, the middle layer is composed of at least five rows of cells as compared with three rows in the middle layer of the bladder epithelium.

The distended ureter has the appearance of Fig. 5. In this condition the folds are lacking, the epithelium is greatly compressed, and the cells and cell-nuclei greatly elongated.

As in the case of the bladder, a comparison of the two conditions shows the number of layers of the epithelium to have been diminished through distension 47.8 per cent, or approximately one-half. The average results of the counts of nuclei lying in the same focal plane between and including the basal and superficial layers in differ-

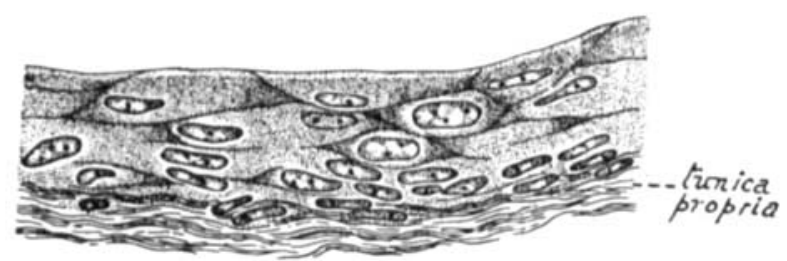

Fig. 5.-Distended ureter epithelium, drawn with camera lucida. $\times 750$.

ent regions of the epithelium of the ureter, under similar conditions of contraction and distension, are recorded in Table 1.

Comparing the percentage decrease of the layers of nuclei in the epithelium of the distended bladder and ureter shows a difference of only .7 per cent. The approximation of this result to the 1.8 per cent difference in decrease of thickness of the epithelium of the bladder and ureter due to distension, indicates a relatively equal distension of the two organs.

By comparing the variations in the epithelium of the bladder and ureter, it is seen that the thickness of that of the bladder decreases 84 per cent, with distension or about one-sixth of its thickness in contraction, while the layers of nuclei in vertical section decrease only 48.5 per cent, or to about one-half the layers in contraction, and that 
the thickness of the epithelium of the ureter decreases 82.2 per cent with distension, or to about one-fifth the thickness in contraction, while the layers of its nuclei decrease 47.8 per cent, or likewise to about one-half the layers in contraction. If cells are only flattened or spread out by distension, then, to be decreased in vertical thickness to one-sixth or one-fifth of its thickness in the contracted condition, as is the entire epithelium, each cell, on the average, would be flattened out to extend over an area five or six times as great as in the contracted state. This would result in a large number of non-nucleated, thin edges of cells in the sections. Such were described by London, but were not observed in this investigation.

An examination of the literature shows that Paneth ('76) followed a series of changes in the bladder epithelium of the dog resulting from different degrees of distension. $\mathrm{He}$ described in the contracted bladder the usual three layers of the epithelium, viz., a superficial layer of broad, thick cells, each overlying several of the cells beneath; a middle layer composed of polygonal or trumpet or tooth-like cells in several layers, and a basal layer composed of more or less cubical or cylindrical cells; and he observed that as the bladder was distended, the cells became flattened, until in the fully distended bladder the epithelium resembled the stratified pavement type. However, he recorded no measurements of the variations nor observed them in much detail.

London ('81) investigated the bladder epithelium of the dog under different conditions of extension, and reached the obvious conclusion that the volume of a single rell, whether contracted or distended, remains the same. He remarked, that, in contraction, the bladder epithelium consisted of five layers of almost cylindrical cells, while in extreme distension it consisted of apparently only one, a layer of flat cells. He accounts for this variation by the supposition that the apparent diminution in layers relates only to the layers of nuclei, that these latter are pushed widely apart by distension, and the flattened cells really exist in their same relative arrangement, but appear as fine lines in section. He concluded, then, that there is no loss of coherence such as would result from a slipping of the cells of one layer between those of the neighboring layers in distension, 
but merely a flattening of the cells of each layer into thin plates. He disregarded the layers of nuclei as indicating the layers of cells. $\mathrm{He}$ further reached a rather peculiar conclusion that, while the return to the normal after distension is devoid of any alteration in previous relation and arrangement of parts, just as in an elastic membrane, in one particular the behavior of the bladder. epithelium is different, namely, that the epithelium of the emptying bladder possessęs a greater elasticity than that of the filling bladder.

Dogiel ('90) claimed that protoplasmic processes bind the cells of one layer to those of another, and Eggeling ('01) described the superficial cells closely applied to the underlying cells with processes extending between the latter.

Herzog ('04), contrary to London, made use of the occurrence and arrangement of nuclei for a study of the layers of the epithelium of the urethra, when under different conditions.

In the preparations used here, the lines interpreted by London as cell boundaries and as representing the thinned edges of flattened cells were not observed, and congo red is considered one of the best counterstains for bringing out cell boundaries.

It is here suggested as possible that in distension, besides the flattening and elongation of the cells due to compression, there is an actual displacement, not only of the cell nuclei, as concluded by London, but also of the cells themselves. An examination of the sections of distended bladder and ureter shows numerous cases of the apparent displacement of the cells of the superficial layer. In Figure 3, for example, there is an indication that adjacent superficial cells have been separated and so that the immediately underlying cells of the middle layer are exposed to the surface. The epithelium, by being thrown into folds during contraction, is evidently allowed to relax more gradually than the muscular wall, and, if such is necessary, a gradual resumption of the former relations of the cells to one another is possible.

Dogiel ('90) pictures a bit of dissociated epthelium from the bladder of the white mouse, stained with picro-carmine, showing filaments establishing actual protoplasmic continuity between the larger superficial cells and the cells of the subjacent layer, and claims 
the continuity thus indicated is a normal relation between the cells. Numerous areas of both partially and totally dissociated cells were to be observed in the folds of the epithelium of the contracted bladder used here, but no protoplasmic filaments as described by Dogiel could be discerned, other than such as could be more safely explained as products of maceration. When maceration is less extensive, though the superficial cells are completely separated (and numerous cases of such could be seen in the preparations), the cells of both layers show smooth boundaries, the superficial layer having only the processes mentioned above as extending between the cells of the subjacent layer. Even these latter processes were absent in the distended condition, the cells having a smooth boundary throughout. Only in manifestly extreme maceration could irreguiar and finely ragged borders be seen. Zenker's fluid was used for fixing here, directly applied, while Dogiel used Müller's fluid and stained with picrocarmine. Congo red was used here and this, as a cytoplasmic stain, is far more efficient for fine processes than is picro-carmine.

\section{Conclusions.}

1. Comparative measurements of the entire wall of the dog's bladder and ureter in approximately the same degree of contraction and in distension by approximately the same pressure show that the thickness of the bladder wall is decreased considerably more than that of the ureter.

2. The extent of distensibility of the ureter is more definitely limited than that of the bladder, undoubtedly due to the more organized arrangement of the supporting tissue and muscular investment of the ureter.

3. The relative effects of distengion are much more evident in the muscularis and tunica propria of the bladder than in these tunics of the ureter, while the thinning effect of the distension upon the epithelium of the two is approximately the same, due to the fact that, in the later stages of the customary contraction of the bladder wall, the epithelium is thrown into more extensive folds than that of the ureter, for, during distension, these folds must first be obliterated before the thickness of the epithelium is much affected by distension. 
4. The epithelium of the ureter is thicker in the contracted state than that of the bladder, but, approximately normal maximum distension produces in the epithelium of both approximately the same percentage of reduction in thickness (about 80 per cent) and approximately the same percentage reduction in the layers of nuclei (about 50 per cent) in both.

5. It is suggested that the diminution in the layers of nuclei may possibly indicate, not only the spreading of the epithelial cells resulting from distension, but, that to some extent at least, in the process of compression, the cells may glide upon one another or be slightly displaced as the epithelium decreases in thickness.

In conclusion acknowledgments are due to Professor Hardesty, at whose suggestion and with whose guidance and advice this investigation was undertaken.

Received for publication, March 15, 1909.

REEERENGES.

Dogrec, A. S. Zur Frage liber das Eplthel der Harnblase. Arch. $\ell$. Mik. Anat., Bd. 35, 1890 , p. 388.

Eoceniva, H. Ueber Deckzellen im Epithel voh Ureter und Harnblase. Anat. Anz., Bd. XX, 1901, p. 116.

Hezzog. F. Beiträge zur Entwicklungsgeschichte und Histologie der Männlichen Harnröhre. Arch. für Mik. Anat., Bd. 63, H. 4, 1904, p. 710.

Lowpox, B. Das Blasenepithel bel verschiedenen Fullungszuständen der Blase. Arch. für Physlol., 1881, p. 317.

Paneth, J. Ueber das Epthel der Harnblase. Sitzber. der K. Akademie der Wissenschaften. Bd. IXXXIV, III, Jull Heft. Wien, 1876. 